\title{
Efficacy and Safety of Cathine (Nor-Pseudoephedrine) in the Treatment of Obesity: A Randomized Dose-Finding Study
}

\author{
Hans Hauner $^{a} \quad$ Ljiljana Hastreiter $^{a} \quad$ Dieter Werdier $^{b} \quad$ Annette Chen-Stute ${ }^{c}$ \\ Jürgen Scholzed Matthias Blüher ${ }^{\mathrm{e}}$ \\ ${ }^{a}$ Else Kröner-Fresenius-Center for Nutritional Medicine, Klinikum rechts der Isar, Technische \\ Universität München, Munich, Germany; ${ }^{b}$ SAM GmbH, Aachen, Germany; ${ }^{\text {cAdipositas- }}$ \\ Zentrum Oberhausen, Oberhausen, Germany; ${ }^{d}$ Centrum für Innere Medizin, Medizinische \\ Polyklinik, Charité-Universitätsmedizin, Berlin, Germany; ${ }^{~}$ Department of Medicine, \\ University of Leipzig, Leipzig, Germany
}

\section{Keywords}

Obesity $\cdot$ Drug treatment $\cdot$ Cathine $\cdot$ Dose-finding study $\cdot$ Safety

\begin{abstract}
Objective: To investigate the efficacy and safety of increasing doses of cathine (nor-pseudoephedrine) as a weight-lowering agent in patients with obesity. Methods: Overweight and obese patients $\left(n=241\right.$, mean BMI $34.6 \pm 3.4 \mathrm{~kg} / \mathrm{m}^{2}$ ) were randomly allocated to one of three doses of cathine (16 mg, $32 \mathrm{mg}, 53.3 \mathrm{mg}$ ) or placebo in addition to a multimodal lifestyle intervention program in a multicenter, double-blind, controlled, dose-finding study for 24 weeks. Primary outcome was weight loss. Results: Treatment with the 3 doses of cathine resulted in a significantly greater weight loss compared to placebo over 24 weeks: $6.5 \pm 4.2 \mathrm{~kg}$ for $16 \mathrm{mg}$ cathine, $6.2 \pm 4.7 \mathrm{~kg}$ for $32 \mathrm{mg}$ cathine, and $9.1 \pm 5.4 \mathrm{~kg}$ for $53.3 \mathrm{mg}$ cathine versus $2.4 \pm 4.4 \mathrm{~kg}$ for placebo (each $\mathrm{p}<0.01$, ANCOVA). The percentage of patients losing $>5 \%$ / $>10 \%$ of initial body weight was significantly greater for all doses of cathine than for placebo (each $\mathrm{p}<0.01$, chi-square test). Heart rate increased dose-dependently (by $1.2 \mathrm{bpm}$ under 16 $\mathrm{mg}, 5.8 \mathrm{bpm}$ under $32 \mathrm{mg}$, and $6.2 \mathrm{bpm}$ under $53.3 \mathrm{mg}$ cathine), but no suspected unexpected serious adverse reactions were noted. The overall dropout rate was $24.9 \%$, with the highest rate in the placebo group (42.3\%). Conclusion: Cathine appears to be an effective weightlowering agent for adjunct treatment of obesity, but additional clinical studies on its efficacy and safety are required.

(c) 2017 The Author(s)

Published by S. Karger GmbH, Freiburg
\end{abstract}

Annette Chen-Stute, Jürgen Scholze, and Matthias Blüher contributed equally to this study.

Prof. Dr. Hans Hauner

Else Kröner-Fresenius-Center for Nutritional Medicine

Klinikum rechts der Isar, Technische Universität München, Uptown Munich, Campus D Georg-Brauchle-Ring 62, 80992 Munich, Germany

hans.hauner@tum.de 
Hauner et al.: Efficacy and Safety of Cathine (Nor-Pseudoephedrine) in the Treatment of Obesity: A Randomized Dose-Finding Study

\section{Introduction}

Obesity is a global health problem with increasing rates not only in the industrialized world but also, and more pronounced, in many developing countries [1,2]. Its main cause is the modern lifestyle with an excess intake of calories, e.g. via energy-dense food, and a lack of physical activity. The associated risk of comorbidities, an impaired quality of life, and an increased mortality rate in obese persons emphasize the need for concerted efforts to prevent and treat obesity more effectively. However, the currently used approaches to manage obesity by lifestyle intervention are insufficient to reduce excess body weight and its adverse consequences adequately. Additional and more effective treatment options are urgently needed.

During the past decades, there were many attempts to develop weight-lowering agents for an adjunct treatment of obesity in addition to lifestyle counseling. Many studies showed disappointing results, and many drugs had to be withdrawn due to side effects or lack of a positive benefit-risk ratio [3-5]. At present, very few anti-obesity agents are available. In Europe, only two weight-lowering drugs are on the market. Both orlistat and the more recently approved GLP-1 mimetic liraglutide at a dosage of $3 \mathrm{mg}$ /day were shown to have a modest to moderate weight-lowering potency in randomized controlled trials [6-8]. In Germany, some agents from the era of amphetamines and amphetamine-like agents are still available and used. The latter drugs were launched more than 40 years ago before strict rules for the approval of weight-lowering agents were introduced and before specific clinical studies became mandatory for approval.

One of these older drugs is cathine or nor-pseudoephedrine. It was originally launched in the 1970s for the short-term treatment of diet-related obesity. Cathine is an alkaloid originally isolated from khat leaves grown in East Africa and the Arab peninsula and is a stable metabolite of cathinone, which is the main psychoactive alkaloid of kath [9-12]. The pharmacological action of cathine includes central (anorexia, increased alertness, increased sensory stimulation, hyperthermia) as well as peripheral effects (increased respiration and heart rate, rise of blood pressure, constipation, urine retention) [11].

So far, there are only limited human data on the effect of cathine as a weight-lowering agent that originate from inadequate and poorly controlled trials $[13,14]$. The aim of this study was, therefore, to assess the efficacy and safety of cathine for weight loss in obese subjects in a randomized controlled clinical trial. As older reports stress the development of tolerance to the action of cathine due to a depletion of neurotransmitters in the central nervous system, it was of particular interest to investigate its effect up to 24 weeks.

\section{Patients and Methods}

\section{Design and Patients}

A multicenter, double-blind, randomized, placebo-controlled dose-finding study was performed in 241 obese patients over 24 weeks. Eligibility criteria included male or female gender, an age between 18 to 65 years, a BMI of $30-40 \mathrm{~kg} / \mathrm{m}^{2}$ or of $27-29.9 \mathrm{~kg} / \mathrm{m}^{2}$ with at least one coexisting risk factor (type 2 diabetes mellitus and/or lipid disorder). Exclusion criteria were a systolic blood pressure exceeding $160 \mathrm{~mm} \mathrm{Hg}$, a diastolic blood pressure exceeding $100 \mathrm{~mm} \mathrm{Hg}$ and/or a heart rate exceeding 100/min after 5 min of rest in a sitting position. Patients were also excluded if they took sympathomimetic or psychotropic drugs (including antidepressants, neuroleptics, sedatives, centrally acting antihypertensives) or received $\beta$-blockers, insulin therapy or any other medication which might alter body weight or interfere with the absorption, metabolism or excretion of cathine. Pre-existing conditions that precluded participation in this study were amongst others cardiovascular and cerebrovascular diseases, pulmonary hypertension, neuropsychiatric disorders, impaired liver or kidney function, chronic obstructive pulmonary disease, bronchial asthma, insomnia, narrow angle glaucoma, hemorrhagic diathesis, and organic reasons for obesity. 
Hauner et al.: Efficacy and Safety of Cathine (Nor-Pseudoephedrine) in the Treatment of Obesity: A Randomized Dose-Finding Study

At the screening visit, the medical history of each patient was recorded followed by physical examination as well as electrocardiographic and laboratory assessment. In women, a pregnancy test was performed. All patients received detailed information about the study protocol and provided written informed consent. The study was conducted at four academic and private trial sites in Germany in accordance with the International Conference on Harmonization Good Clinical Practice Guidelines. The study protocol was approved by the Ethics Committees of the participating centers.

\section{Treatment and Study Medication}

After a 2-week placebo run-in period, patients were randomly allocated to four treatment arms. Once daily, they received a defined solution containing 0,16, 32 or $53.3 \mathrm{mg}$ cathine hydrochloride (Antiadipositum X-112 $\mathrm{T}^{\circledR}$ now renamed Alvalin ${ }^{\circledR}$; RIEMSER Pharma, Riems, Germany). After 12 weeks, there was a comprehensive assessment of the tolerability of the drug, and if there were no serious drug-related adverse events the administration of the drug was continued for another 12 weeks, resulting in a total treatment period of 24 weeks. Regular visits at the study centers were held every 2 weeks over the entire period of treatment. In addition, follow-up visits were performed at weeks 28 and 52, i.e. 4 and 28 weeks after termination of active treatment. At each visit, anthropometric variables, electrocardiography, and other outcome variables including potential adverse events were assessed. Anthropometric measurements (body weight, waist circumference) were performed using established procedures in a standardized manner.

\section{Lifestyle Program}

Each patient, independent of group allocation, received structured counseling sessions using an established and validated intervention program [15] which was adapted to the specific requirements of the study design. In addition, the recommendations were individually tailored based on the analysis of dietary protocols. The aim was to achieve an energy deficit of 500-600 kcal/day. The level of daily physical activity was assessed using a pedometer. Patients were recommended to increase their physical activity up to 5,000 to 10,000 steps/day, depending on baseline activity using a pedometer for self-monitoring.

\section{Study End Points}

Primary outcome variable of this study was the change in body weight after 24 weeks of treatment.

Secondary end points included percentage of patients with weight loss $>5 \%$ and $>10 \%$, changes of BMI, waist circumference (WC), waist-hip ratio (WHR), serum lipids and glucose, adverse event outcome as well as changes in blood pressure, heart rate and QT interval.

\section{Blood Collection and Biochemical Analyses}

Blood was taken from patients in the fasted state at baseline and then 4, 8, 12, 16, 20, and 24 weeks after start of treatment. TSH and HbA1c were evaluated only at baseline. Complete blood count, creatinine, fasting glucose, total cholesterol, LDL-cholesterol, HDL-cholesterol, triglycerides, uric acid, transaminases, and $\gamma$-GT were measured at each time of blood collection.

\section{Anxiety and Depression}

To evaluate symptoms of anxiety and depression patients were asked to complete the Hospital and Anxiety and Depression Score (HADS) questionnaire [16], at baseline and at several visits during treatment and at the 4-week follow-up. The item scores for anxiety and depression were calculated separately and are given as subscale scores.

\section{Statistical Analysis}

Statistical analyses were performed using SAS ${ }^{\circledR} 9.2$ (SAS Institute Inc., Cary, NC, USA). The main aim of the study was to evaluate the efficacy and safety of different doses of cathine compared to placebo for weight loss and maintenance of reduced weight when administrated in conjunction with a lifestyle modification program over a period of 24 weeks in diet-induced obese patients. The primary efficacy measure was the reduction of body weight upon the different treatment doses of cathine compared to placebo at the end of the study. ANCOVA with weight loss after 24 weeks as dependent variable, treatment group as independent variable, and baseline weight as covariate was used for statistical primary target analysis. Thereafter, the significant influence of treatment group on weight loss compared to placebo was analyzed by a TukeyKramer Test due to the multiple comparisons. Secondary efficacy parameters were change of WC and WHR, 
Hauner et al.: Efficacy and Safety of Cathine (Nor-Pseudoephedrine) in the Treatment of Obesity: A Randomized Dose-Finding Study

serum lipids, fasting glucose, BMI, blood pressure, heart rate, and the proportions of patients achieving a weight loss of $>5 \%$ and $>10 \%$ at the end of study.

The sample size of 60 patients/treatment group (240 patients in total) was calculated by assuming a clinically relevant difference of $d=3 \mathrm{~kg}$, a standard deviation of $\sigma=3.2 \mathrm{~kg}$, a $\beta$-level of 0.10 , and a dropout rate of $36 \%$. The SAS ${ }^{\circledR}$ procedure PROC Plan was used for generating the randomization list.

All patients with analyzable body weight data at baseline and after 24 weeks of therapy were included into the completers' analysis. In the case of non-completers with body weight data available from the beginning of treatment and at least one following study visit, an intention-to-treat (ITT) analysis was applied in which missing weight data were replaced by their last observed value (LOCF).

\section{Results}

\section{Recruitment and Baseline Data}

A total of 262 patients were screened, of whom 241 were enrolled in the study (fig. 1). During the initial 2-week placebo run-in period, a mean weight loss ( \pm SD) of $0.6 \pm 1.5 \mathrm{~kg}$ was observed. After start of treatment, 4 patients dropped out before the next visit. Therefore, data from 237 patients were analyzed on a modified ITT basis. During the active treatment period, 59 patients discontinued the study (overall dropout rate 24.9\%). Most patients dropped out from the placebo group (42.3\%). Their main reasons were poor compliance and dissatisfaction with weight loss $(n=14)$. In the 4 groups combined, 12 individuals withdrew due to adverse drug reactions (ADRs). Finally, 178 patients completed the trial after 24 weeks. This study population was used for a completers' analysis.

The baseline characteristics of the 237 patients after randomization are presented in table 1. Most study patients were women (75.9\%). The mean age of all patients was $48.5 \pm$ 10.4 years, the mean baseline BMI was $34.6 \pm 3.4 \mathrm{~kg} / \mathrm{m}^{2}$. Age and baseline BMI were comparable between the four treatment groups. $12.2 \%$ of the patients suffered from type 2 diabetes and $34.6 \%$ from hypertension with a similar distribution across the four treatment arms (data not shown).

\section{Primary End Point}

The mean weight of the patients declined constantly in all active treatment groups until the end of the study (fig. 2). Mean weight loss ( \pm SD) after 24 weeks was $6.5 \pm 4.2 \mathrm{~kg}$ under $16 \mathrm{mg}$ cathine, $6.2 \pm 4.7 \mathrm{~kg}$ under $32 \mathrm{mg}$ cathine, and $9.1 \pm 5.4 \mathrm{~kg}$ under $53.3 \mathrm{mg}$ cathine but only $2.4 \pm 5.4 \mathrm{~kg}$ in the placebo group. The respective levels of weight loss in the completers' analysis were $7.6 \pm 3.7 \mathrm{~kg}$ under $16 \mathrm{mg}$ cathine $(\mathrm{n}=48), 7.0 \pm 4.6 \mathrm{~kg}$ under $32 \mathrm{mg}$ cathine (n $=49)$, and $9.8 \pm 5.6 \mathrm{~kg}$ under $53.3 \mathrm{mg}$ cathine $(\mathrm{n}=47)$ versus $3.7 \pm 5.0 \mathrm{~kg}$ under placebo treatment $(\mathrm{n}=34)$. In both types of analysis, weight loss was significantly greater in the active treatment groups compared to placebo (each $\mathrm{p}<0.02$, ANCOVA with Tukey-Kramer Test).

In the ITT population, mean WC decreased over 24 weeks by $5.4 \pm 7.2 \mathrm{~cm}$ under $16 \mathrm{mg}$ cathine, by $5.1 \pm 4.7 \mathrm{~cm}$ under $32 \mathrm{mg}$ cathine, by $7.5 \pm 5.7 \mathrm{~cm}$ under $53.3 \mathrm{mg}$ cathine, and by $1.6 \pm 5.9 \mathrm{~cm}$ under placebo treatment (fig. 2). Again, the differences between the three doses of cathine and placebo were statistically significant (each $\mathrm{p}<0.01$, ANCOVA with TukeyKramer Test).

Figure 3 shows the relative proportions of patients achieving a weight loss of $>5 \%$ and $>10 \%$ over 24 weeks versus baseline weight for the ITT (LOCF) population. The percentage of patients achieving the defined weight reduction was dose-dependent. In the highest cathine treatment group, $78.3 \%$ lost more than $5 \%$ of their initial weight and $41.7 \%$ lost more than $10 \%$. Significantly more individuals in the cathine treatment groups had a weight reduction of $>5 \%$ and $>10 \%$ than in the placebo group (each $p<0.01$, chi square test). 
Hauner et al.: Efficacy and Safety of Cathine (Nor-Pseudoephedrine) in the Treatment of Obesity: A Randomized Dose-Finding Study

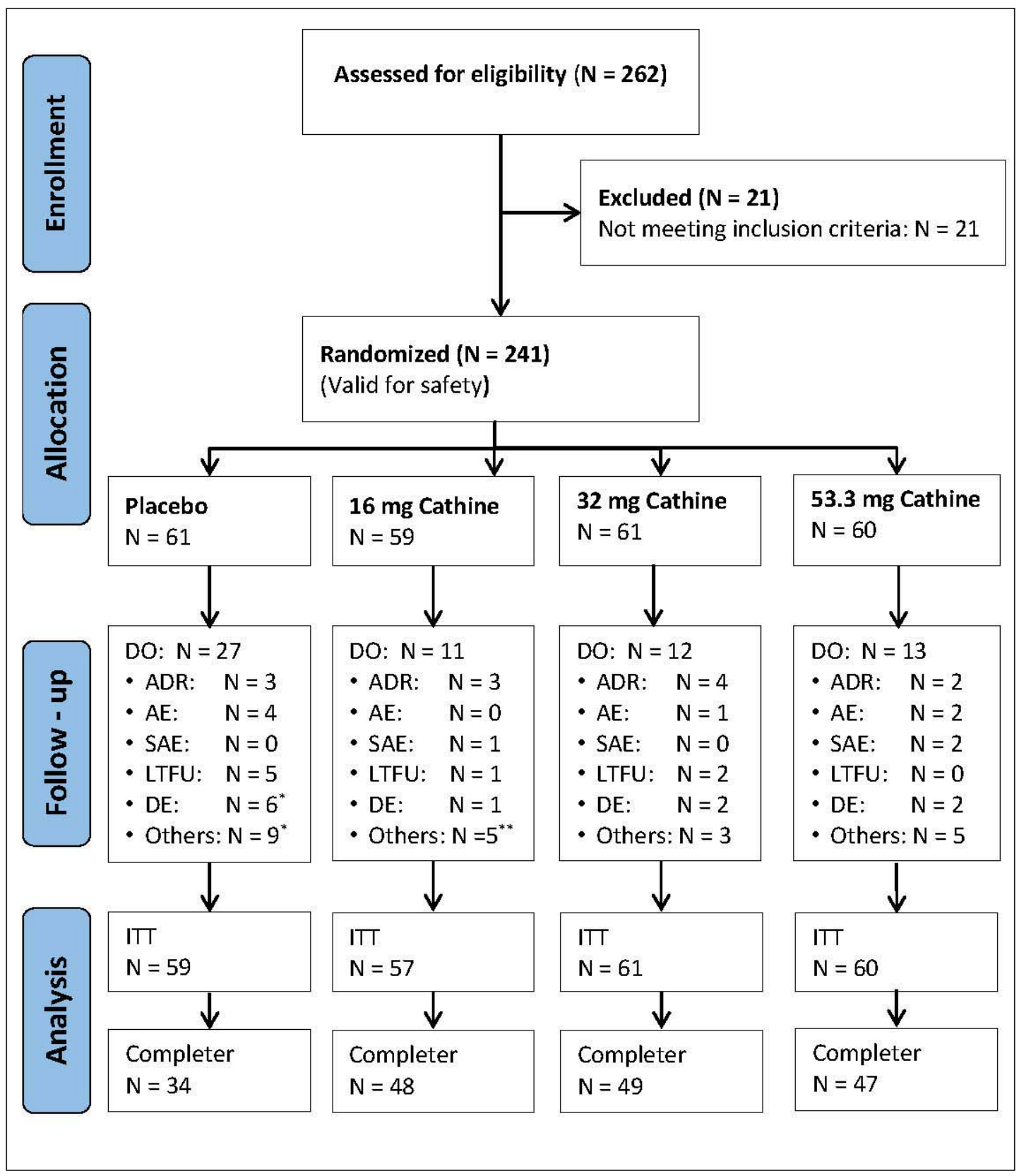

Fig. 1. Study flow of patients' enrollment, randomization, withdrawal from treatment, and analysis. ${ }^{*} 1$ patient dropped out before visit $2{ }^{* *} 2$ patients dropped out before visit 2 . LTFU = Lost to follow-up; DO = dropout; $\mathrm{DE}$ = deficient efficacy; $\mathrm{ADR}$ = adverse drug reaction; $\mathrm{AE}$ = adverse event; $\mathrm{SAE}$ = serious adverse reaction

\section{Cardiovascular Risk Factors}

The changes in lipid parameters and fasting plasma glucose over 12 and 24 weeks compared to baseline levels are displayed in table 2. Total cholesterol and LDL-cholesterol were significantly lower in the $16 \mathrm{mg}$ and the $53.3 \mathrm{mg}$ cathine groups after 12 and 24 weeks. There were no significant changes in HDL-cholesterol after 12 weeks. HDL-cholesterol significantly increased after 24 weeks in the placebo group and the group receiving $32 \mathrm{mg}$ cathine. Triglycerides were significantly reduced after 12 weeks with $16 \mathrm{mg}$ cathine and after 24 
Table 1. Baseline patient characteristics of the ITT population $(n=237)^{*}$

\begin{tabular}{|c|c|c|c|c|c|}
\hline Characteristic & $\begin{array}{l}\text { Placebo } \\
(n=59)\end{array}$ & $\begin{array}{l}16 \text { mg cathine } \\
(n=57)\end{array}$ & $\begin{array}{l}32 \text { mg cathine } \\
(n=61)\end{array}$ & $\begin{array}{l}53.3 \mathrm{mg} \text { cathine } \\
(\mathrm{n}=60)\end{array}$ & $\begin{array}{l}\text { All patients } \\
(\mathrm{n}=237)\end{array}$ \\
\hline Age, years & $47.5 \pm 11.0$ & $48.8 \pm 10.4$ & $48.5 \pm 10.3$ & $49.3 \pm 10.2$ & $48.5 \pm 10.4$ \\
\hline Gender, M/F & $17 / 42$ & $10 / 47$ & $21 / 40$ & $9 / 51$ & $57 / 180$ \\
\hline Height, cm & $171.0 \pm 8.3$ & $167.0 \pm 7.5$ & $170.3 \pm 8.0$ & $168.5 \pm 7.8$ & $169.2 \pm 8.0$ \\
\hline Weight, kg & $101.6 \pm 15.6$ & $95.5 \pm 13.2$ & $102.0 \pm 15.0$ & $98.5 \pm 14.6$ & $99.4 \pm 14.8$ \\
\hline BMI, $\mathrm{kg} / \mathrm{m}^{2}$ & $34.6 \pm 3.3$ & $34.1 \pm 3.4$ & $35.0 \pm 3.4$ & $34.6 \pm 3.6$ & $34.6 \pm 3.4$ \\
\hline $\mathrm{HC}, \mathrm{cm}$ & $119.2 \pm 10.0$ & $116.4 \pm 15.5$ & $119.7 \pm 9.2$ & $119.1 \pm 9.8$ & $119.1 \pm 9.7$ \\
\hline $\mathrm{WC}, \mathrm{cm}$ & $109.8 \pm 12.1$ & $106.6 \pm 10.8$ & $109.0 \pm 12.1$ & $107.6 \pm 11.3$ & $108.3 \pm 11.6$ \\
\hline Systolic BP, mm Hg & $128.0 \pm 13.9$ & $130.8 \pm 15.2$ & $128.2 \pm 13.5$ & $133.8 \pm 15.9$ & $130.2 \pm 14.7$ \\
\hline Diastolic BP, mm Hg & $82.3 \pm 7.3$ & $84.4 \pm 7.6$ & $83.5 \pm 8.8$ & $85.9 \pm 8.9$ & $84.0 \pm 8.2$ \\
\hline Heart rate, bpm & $68.7 \pm 11.0$ & $69.7 \pm 10.0$ & $69.3 \pm 12.4$ & $67.2 \pm 9.9$ & $68.7 \pm 10.9$ \\
\hline Total cholesterol, mmol/l & $5.6 \pm 1.1$ & $5.9 \pm 1.0$ & $5.5 \pm 1.1$ & $5.7 \pm 0.9$ & $5.7 \pm 1.0$ \\
\hline LDL-cholesterol, mmol/l & $3.5 \pm 1.0$ & $3.7 \pm 0.9$ & $3.3 \pm 0.9$ & $3.6 \pm 0.9$ & $3.5 \pm 0.9$ \\
\hline HDL-cholesterol, mmol/l & $1.4 \pm 0.4$ & $1.5 \pm 0.4$ & $1.4 \pm 0.4$ & $1.5 \pm 0.4$ & $1.5 \pm 0.4$ \\
\hline Triglycerides, mmol/l & $1.6 \pm 0.8$ & $1.7 \pm 0.9$ & $1.8 \pm 0.9$ & $1.6 \pm 0.8$ & $1.7 \pm 0.8$ \\
\hline Fasting glucose, mmol/l & $5.4 \pm 1.7$ & $5.1 \pm 0.8$ & $5.6 \pm 1.3$ & $5.5 \pm 1.7$ & $5.4 \pm 1.4$ \\
\hline $\mathrm{HbA1c} \%$ & $2.7 \pm 0.1$ & $2.7 \pm 0.0$ & $2.7 \pm 0.1$ & $2.7 \pm 0.1$ & $2.7 \pm 0.1$ \\
\hline
\end{tabular}

$\mathrm{BP}=$ Blood pressure; $\mathrm{HC}=$ hip circumference; $\mathrm{M} / \mathrm{F}=$ male $/$ female; $\mathrm{WC}=$ waist circumference.

*Data are presented as mean \pm SD.

Table 2. Changes in obesity-associated risk factors from baseline value after 12 and 24 weeks (mean \pm SD of remaining patients at time points)

\begin{tabular}{|c|c|c|c|c|c|c|c|c|}
\hline & \multicolumn{4}{|c|}{$\begin{array}{l}\text { Change after } 12 \text { weeks } \\
(\mathrm{n}=211)\end{array}$} & \multicolumn{4}{|c|}{$\begin{array}{l}\text { Change after } 24 \text { weeks } \\
(n=178)\end{array}$} \\
\hline & placebo & $\begin{array}{l}16 \mathrm{mg} \\
\text { cathine }\end{array}$ & $\begin{array}{l}32 \mathrm{mg} \\
\text { cathine }\end{array}$ & $\begin{array}{l}53.3 \mathrm{mg} \\
\text { cathine }\end{array}$ & placebo & $\begin{array}{l}16 \mathrm{mg} \\
\text { cathine }\end{array}$ & $\begin{array}{l}32 \mathrm{mg} \\
\text { cathine }\end{array}$ & $\begin{array}{l}53.3 \mathrm{mg} \\
\text { cathine }\end{array}$ \\
\hline $\begin{array}{l}\text { Total cholesterol, mg/dl } \\
\text { (p value) }\end{array}$ & $\begin{array}{l}-0.0 \pm 0.6 \\
(0.6944)\end{array}$ & $\begin{array}{l}-0.4 \pm 0.7 \\
(0.0004)\end{array}$ & $\begin{array}{l}-0.3 \pm 0.8 \\
(0.0280)\end{array}$ & $\begin{array}{l}-0.5 \pm 0.6 \\
(<0.0001)\end{array}$ & $\begin{array}{l}0.2 \pm 0.6 \\
(0.0307)\end{array}$ & $\begin{array}{l}-0.4 \pm 0.6 \\
(<0.0001)\end{array}$ & $\begin{array}{l}-0.1 \pm 0.8 \\
(0.5696)\end{array}$ & $\begin{array}{l}-0.4 \pm 0.7 \\
(0.0017)\end{array}$ \\
\hline $\begin{array}{l}\text { LDL-cholesterol, mg/dl } \\
\text { ( } \mathrm{p} \text { value) }\end{array}$ & $\begin{array}{l}-0.1 \pm 0.5 \\
(0.1490)\end{array}$ & $\begin{array}{l}-0.3 \pm 0.6 \\
(0.0008)\end{array}$ & $\begin{array}{l}-0.1 \pm 0.6 \\
(0.1362)\end{array}$ & $\begin{array}{l}-0.5 \pm 0.5 \\
(<0.0001)\end{array}$ & $\begin{array}{l}0.0 \pm 0.6 \\
(0.8621)\end{array}$ & $\begin{array}{l}-0.3 \pm 0.5 \\
(0.0004)\end{array}$ & $\begin{array}{l}-0.1 \pm 0.8 \\
(0.5427)\end{array}$ & $\begin{array}{l}-0.3 \pm 0.6 \\
(0.0019)\end{array}$ \\
\hline $\begin{array}{l}\text { HDL-cholesterol, mg/dl } \\
\text { (p value) }\end{array}$ & $\begin{array}{l}0.0 \pm 0.2 \\
(0.4984)\end{array}$ & $\begin{array}{l}-0.0 \pm 0.2 \\
(0.4938)\end{array}$ & $\begin{array}{l}-0.0 \pm 0.2 \\
(0.5744)\end{array}$ & $\begin{array}{l}-0.0 \pm 0.2 \\
(0.1783)\end{array}$ & $\begin{array}{l}0.1 \pm 0.2 \\
(0.0066)\end{array}$ & $\begin{array}{l}0.0 \pm 0.2 \\
(0.8526)\end{array}$ & $\begin{array}{l}0.2 \pm 0.4 \\
(0.0076)\end{array}$ & $\begin{array}{l}0.0 \pm 0.2 \\
(0.2435)\end{array}$ \\
\hline $\begin{array}{l}\text { Triglycerides, mg/dl } \\
\text { (p value) }\end{array}$ & $\begin{array}{l}-0.0 \pm 0.7 \\
(0.8799)\end{array}$ & $\begin{array}{l}-0.3 \pm 0.8 \\
(0.0395)\end{array}$ & $\begin{array}{l}-0.1 \pm 0.7 \\
(0.2163)\end{array}$ & $\begin{array}{l}-0.1 \pm 0.5 \\
(0.3553)\end{array}$ & $\begin{array}{l}0.3 \pm 0.9 \\
(0.0930)\end{array}$ & $\begin{array}{l}-0.3 \pm 0.8 \\
(0.0101)\end{array}$ & $\begin{array}{l}-0.4 \pm 0.7 \\
(0.0016)\end{array}$ & $\begin{array}{l}-0.2 \pm 0.5 \\
(0.0392)\end{array}$ \\
\hline $\begin{array}{l}\text { Fasting glucose, } \mathrm{mg} / \mathrm{dl} \\
\text { (p value) }\end{array}$ & $\begin{array}{l}0.1 \pm 0.7 \\
(0.5703)\end{array}$ & $\begin{array}{l}0.1 \pm 0.8 \\
(0.2383)\end{array}$ & $\begin{array}{l}-0.0 \pm 0.8 \\
(0.7789)\end{array}$ & $\begin{array}{l}-0.1 \pm 1.4 \\
(0.5552)\end{array}$ & $\begin{array}{l}0.3 \pm 1.2 \\
(0.1710)\end{array}$ & $\begin{array}{l}0.0 \pm 0.8 \\
(0.9164)\end{array}$ & $\begin{array}{l}-0.2 \pm 0.8 \\
(0.1088)\end{array}$ & $\begin{array}{l}-0.4 \pm 1.2 \\
(0.0377)\end{array}$ \\
\hline
\end{tabular}

weeks of treatment with $16 \mathrm{mg}, 32 \mathrm{mg}$, and $53.3 \mathrm{mg}$ cathine, but there was no effect on triglycerides in the placebo group. Fasting glucose was unchanged with the exception of 24 weeks in the group receiving $53.3 \mathrm{mg}$ cathine/day (table 2 ).

We analyzed the ITT population $(\mathrm{N}=237)$ for changes in blood pressure and heart rate during intervention (table 3 ). There were no significant decreases in mean systolic and diastolic blood pressure after 12 and 24 weeks versus baseline in the 4 study groups. However, 
Hauner et al.: Efficacy and Safety of Cathine (Nor-Pseudoephedrine) in the Treatment of Obesity: A Randomized Dose-Finding Study

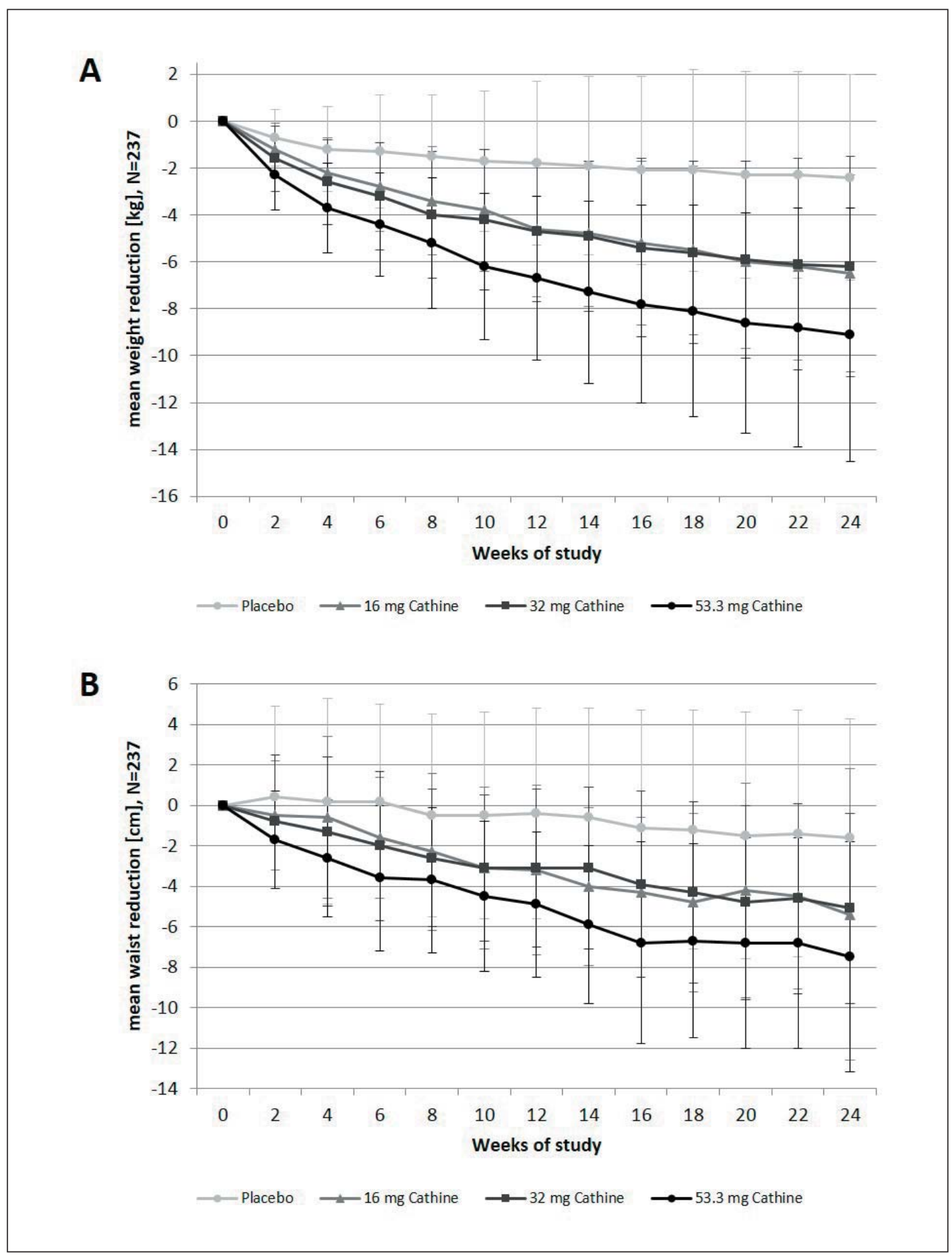

Fig. 2. Changes in weight $(\mathrm{kg})$ and waist circumference $(\mathrm{cm})($ mean $\pm \mathrm{SD})$ in the ITT $(\mathrm{LOCF})$ population $(\mathrm{n}=$ 237). ITT = Intention-to-treat analysis; LOCF = last observation carried forward method. 
Hauner et al.: Efficacy and Safety of Cathine (Nor-Pseudoephedrine) in the Treatment of Obesity: A Randomized Dose-Finding Study

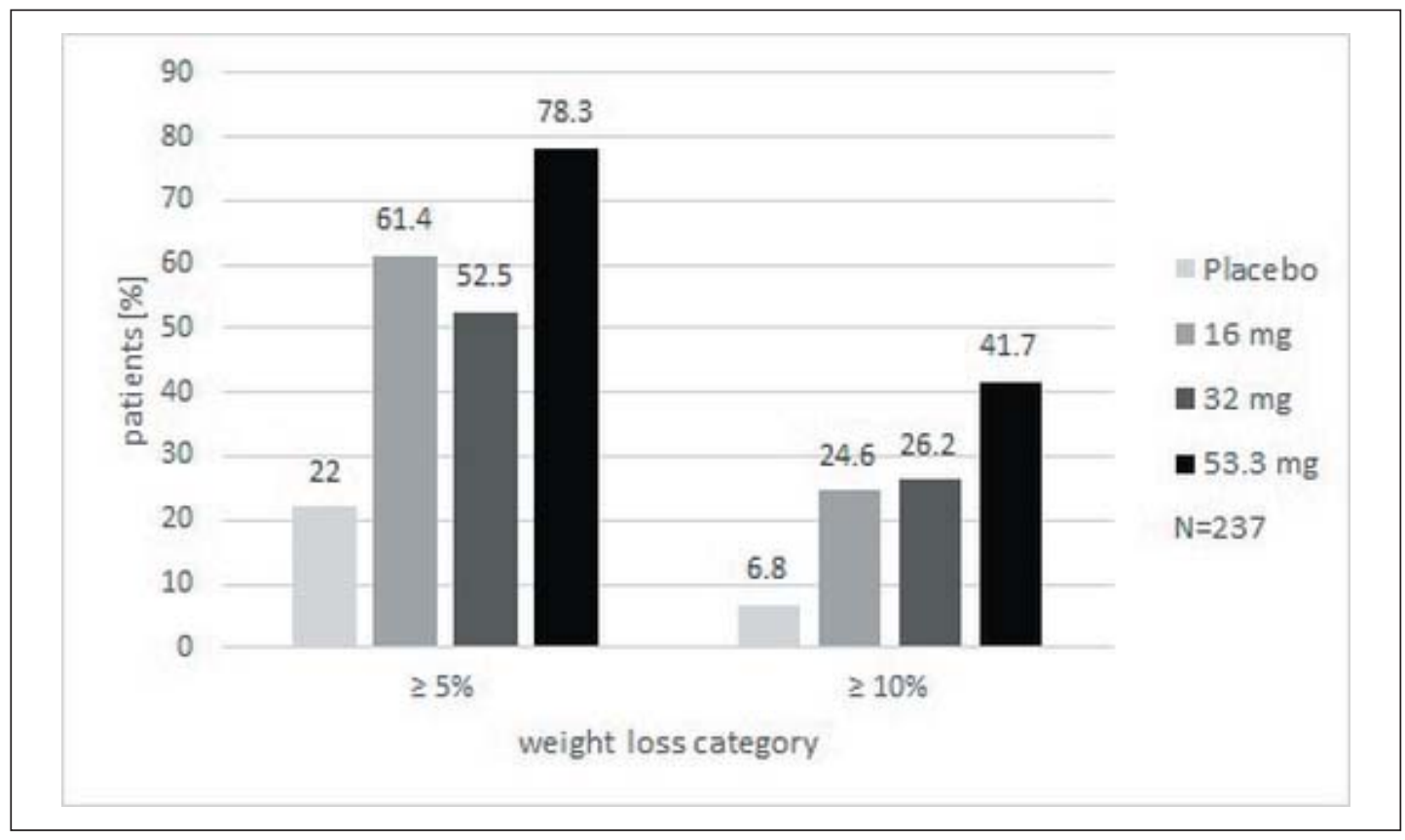

Fig. 3. Patients who lost $>5 \%$ and $>10 \%$ of their baseline body weight at week 24 (ITT (LOCF) population, $\mathrm{n}=237)$.

Table 3. Changes in blood pressure and heart rate (mean \pm SD) after 24 weeks for the ITT (LOCF) population, $\mathrm{n}=237$

\begin{tabular}{lllll}
\hline & \multicolumn{4}{l}{ Change after 24 weeks (n=237) } \\
\cline { 2 - 5 } & placebo & 16 mg cathine & 32 mg cathine & 53.3 mg cathine \\
\hline $\begin{array}{l}\text { Systolic blood pressure, mm Hg } \\
\text { (p value) }\end{array}$ & $\begin{array}{l}-1.4 \pm 12.6 \\
(0.0892)\end{array}$ & $\begin{array}{l}-5.0 \pm 13.8 \\
(0.0057)\end{array}$ & $\begin{array}{l}-0.8 \pm 12.3 \\
(0.0281)\end{array}$ & $\begin{array}{l}-4.3 \pm 11.4 \\
(0.0012)\end{array}$ \\
\hline $\begin{array}{l}\text { Diastolic blood pressure, mm Hg } \\
\text { (p value) }\end{array}$ & $\begin{array}{lll}0.2 \pm 7.4 \\
(0.0830)\end{array}$ & $\begin{array}{l}-2.0 \pm 7.9 \\
(0.0046)\end{array}$ & $\begin{array}{l}0.2 \pm 8.3 \\
(0.4409)\end{array}$ & $\begin{array}{l}-1.5 \pm 7.6 \\
(0.0933)\end{array}$ \\
\hline $\begin{array}{l}\text { Heart rate, bpm } \\
\text { (p value) }\end{array}$ & $-1.4 \pm 10.3$ & $\begin{array}{l}1.2 \pm 8.7 \\
(0.1719)\end{array}$ & $\begin{array}{l}5.8 \pm 11.4 \\
(0.8820)\end{array}$ & $\begin{array}{l}6.2 \pm 10.3 \\
(0.7797)\end{array}$ \\
\hline
\end{tabular}

in those participants with elevated blood pressure at baseline (systolic blood pressure $\geq 140$ $\mathrm{mm} \mathrm{Hg}$ and $<160 \mathrm{~mm} \mathrm{Hg}$ and/or diastolic blood pressure $\geq 90 \mathrm{~mm} \mathrm{Hg}$ and $<100 \mathrm{~mm} \mathrm{Hg}$ ), a significant decrease in blood pressure was observed (systolic blood pressure $-8.1 \pm 11.7 \mathrm{~mm}$ $\mathrm{Hg}$, diastolic blood pressure $-3.7 \pm 7.7 \mathrm{~mm} \mathrm{Hg}$, $\mathrm{p}<0.05$ vs. baseline, ITT analysis, patients under cathine combined, $\mathrm{n}=71$ ).

Treatment with cathine produced a moderate, dose-dependent, but not significant increase in heart rate. After 24 weeks, the mean increase in heart rate was $1.2 \pm 8.7 \mathrm{bpm}$ under $16 \mathrm{mg}$ cathine, $5.8 \pm 11.4 \mathrm{bpm}$ under $32 \mathrm{mg}$ cathine, and $6.2 \pm 10.3 \mathrm{bpm}$ under $53.3 \mathrm{mg}$ cathine. In the placebo group a modest decrease of heart rate by $1.4 \pm 10.3 \mathrm{bpm}$ was observed (fig. 4). Comparable results were obtained in the completer population (data not shown). In addition, electrocardiography analysis performed in regular intervals in all patients did not reveal any abnormalities (data not shown). 
Hauner et al.: Efficacy and Safety of Cathine (Nor-Pseudoephedrine) in the Treatment of Obesity: A Randomized Dose-Finding Study

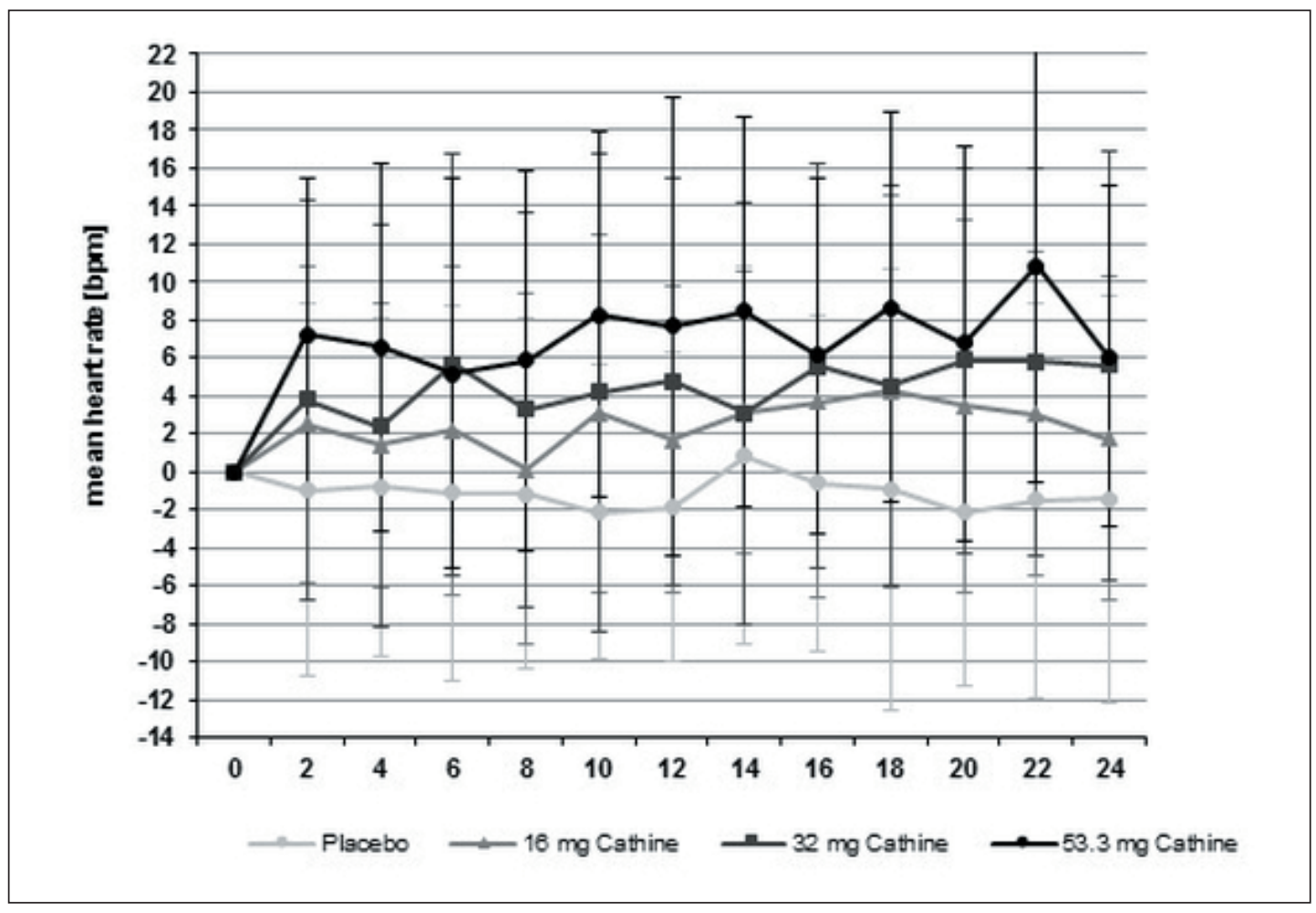

Fig. 4. Changes in heart rate over 24 weeks under treatment with cathine or placebo (mean \pm SD) (completers population, $\mathrm{n}=178$ ).

\section{Anxiety and Depression Score}

The HADS depression subscore improved significantly from baseline to the assessment after 24 weeks. Improvements were seen in all groups. With the exception of the $53.3 \mathrm{mg}$ group, significant changes for the anxiety subscores were not observed between any of the assessments (supplementary table 1, available at http://content.karger.com/ProdukteDB/ produkte.asp?doi=478098).

\section{Adverse Events and Tolerability}

During the clinical trial, a total of 243 adverse events were documented. No suspected unexpected serious adverse reactions were reported. Eight of the adverse events were serious, but without any causal relationship to the study medication. 60 adverse events were classified as non-serious ADRs. These reactions included, amongst others, cardiovascular events (e.g. tachycardia, increase in blood pressure) as well as events related to the central nervous system (e.g. restlessness, sleep disorder, depression). The number of ADRs increased in proportion to the cathine dosage the patients received. Table 4 presents all ADRs occurring in the treatment as well as in the placebo group. Due to ADRs, a total of 12 patients dropped out from the study (table 4).

\section{Follow-Up after Intervention}

A total of 141 patients who completed the clinical trial attended a follow-up visit at week 4 or 28 after stopping the active intervention. In this period, patients had received neither study medication nor any other supportive measures to maintain their weight loss. The mean

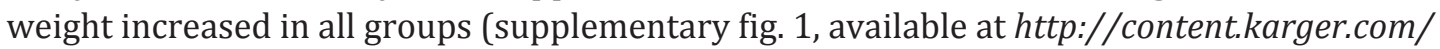


Hauner et al.: Efficacy and Safety of Cathine (Nor-Pseudoephedrine) in the Treatment of Obesity: A Randomized Dose-Finding Study

Table 4. Total ADRs for each treatment group and ADRs leading to drop out of patients before the end of the study

\begin{tabular}{|c|c|c|c|c|}
\hline ADR & Placebo & $16 \mathrm{mg}$ cathine & $32 \mathrm{mg}$ cathine & $53.3 \mathrm{mg}$ cathine \\
\hline Tachycardia & & 2 & & \\
\hline Palpitations & & & & 5 \\
\hline Chest pain & & & & 2 \\
\hline Hypertension & & 1 & 1 & 3 \\
\hline Ischemia & & & & 1 \\
\hline Ventricular extrasystoles & & & & 1 \\
\hline ECG QT prolonged & & & & 1 \\
\hline Dizziness & & 1 & & \\
\hline Syncope & 1 & & & \\
\hline Headache & 1 & & 1 & 1 \\
\hline Restlessness & 1 & 1 & 1 & 3 \\
\hline Psychomotor hyperactivity & & & 1 & \\
\hline Sleep disorder & 1 & & 1 & \\
\hline Depression & 1 & & & 1 \\
\hline Panic attack & & & 1 & \\
\hline Hot flush & & & 3 & \\
\hline Dry mouth & & 2 & & 2 \\
\hline Hyperhidrosis & & & & 2 \\
\hline Hepatic enzyme increased & & & 1 & \\
\hline Transaminases increased & & & 1 & \\
\hline GGT increased & & 1 & & \\
\hline Blood glucose increased & 1 & & & \\
\hline Hyperglycemia & 1 & & & \\
\hline Weight increased & 1 & & & \\
\hline Muscle spasms & & 1 & & 1 \\
\hline Hypersensitivity & & 1 & & \\
\hline Leukopenia & 1 & & & 2 \\
\hline Peripheral coldness & & & & 1 \\
\hline Constipation & & 1 & & \\
\hline Paresthesia & & & 1 & \\
\hline Thirst & & & 1 & \\
\hline Erectile dysfunction & & & 1 & \\
\hline Total reported ADRs & 9 & 11 & 14 & 26 \\
\hline Drop outs due to an ADR & $3^{a}$ & $3^{b}$ & $4^{c}$ & $2^{d}$ \\
\hline
\end{tabular}

${ }^{a} 1 \times$ headache, $1 \times$ depression, $1 \times$ hyperglycemia.

b $1 \times$ dizziness, $1 \times$ GGT increased, $1 \times$ hypersensitivity.

c $1 \times$ sleep disorder, $1 \times$ hot flush, $1 \times$ hepatic enzyme increased, $1 \times$ transaminases increased.

$\mathrm{d} 1 \times$ ischemia, $1 \times$ dry mouth.

ProdukteDB/produkte.asp?doi=478098), but still remained below baseline. Weight regain in the cathine groups was slightly higher than in the placebo group. During the follow-up period, no serious adverse reactions were reported (data not shown).

\section{Discussion}

The present study is the first phase II dose-finding study to investigate the effect of cathine on weight reduction in obese patients. The results suggest that the drug has a significant weight-reducing effect for all of the doses tested. The $53.3 \mathrm{mg}$ dose was more effective 
Hauner et al.: Efficacy and Safety of Cathine (Nor-Pseudoephedrine) in the Treatment of Obesity: A Randomized Dose-Finding Study

than the two lower doses. At the maximum dosage, mean weight loss was $9.1 \mathrm{~kg}$ as compared to $2.4 \mathrm{~kg}$ under placebo treatment after 24 weeks. Surprisingly, the weight loss at doses of 16 and $32 \mathrm{mg} /$ day was similar. This could be due to a lower compliance to the concomitant diet in the $32 \mathrm{mg}$ group, but cannot be fully explained.

All patients received an intensive multimodal lifestyle modification program comprising an energy-restricted diet and an increase in physical activity. The principal finding of this randomized controlled trial on cathine was that this agent is effective and rather safe to support weight loss in obese subjects over this short-term period. To date, our knowledge on the weight-lowering potential of cathine is mainly based on very small studies with a limited number of patients in the 1970s [13,14], although cathine has been used for the treatment of obesity for more than 40 years. In Germany, nearly 1 million obese individuals were treated with cathine in the past 10 years. The incidence of reported ADRs was low - less than 40 spontaneous case reports from healthcare professionals were collected in this time [17]. However, it should be stressed that substantial underreporting of ADRs in primary care is a known problem of such registries based on self-reporting.

As expected from a drug with sympathomimetic action, cathine increased heart rate, with a mean increase at the two highest concentrations of about $6 \mathrm{bpm}$. The reduction of blood pressure was smaller than expected by the extent of weight loss, but was seen in those with moderately elevated blood pressure at baseline. This observation is similar to the experience with sibutramine, which also exhibits a rather modest decrease in blood pressure, particularly in those patients with elevated blood pressure $[15,18]$. Electrocardiography analysis performed in regular intervals in all patients did not reveal any abnormalities. It is important to note that high-risk patients were excluded. Therefore, the safety data observed in this trial are not representative for the general obese population, and additional larger studies with longer exposure are required to obtain more reliable information.

After premature termination of the SCOUT study due to the adverse long-term effect of sibutramine on the cardiovascular system and the withdrawal of rimonabant, assessment of potential adverse events is of crucial importance for any centrally acting weight-lowering drug. The results of this study indicate that cathine has a similar risk profile as sibutramine with regard to activation of the sympathetic nervous system. Nevertheless, even in the group receiving the highest dose of cathine no serious adverse reactions were observed. No signs of any kind of misuse or abuse were noted. Thus, no new safety issues were identified during this clinical trial, although the sample size was too small to exclude other rare adverse events.

According to the literature, it is assumed that cathine has only a transient weight-lowering activity due to the development of tolerance or tachyphylaxia. Therefore, the original recommendation was to use cathine only for short treatment intervals of 4-6 weeks. This study was designed to examine the efficacy of cathine treatment for up to 24 weeks in a controlled clinical setting. Our results indicate that there is no attenuation or even loss of efficacy concerning weight reduction over this period. Weight loss continued, even between week 12 and 24. Thus, this trial suggests that administration of cathine may have a longer duration of action and may be similar to noradrenergic drugs such as sibutramine and phentermine. Nevertheless, in view of the chronic nature of obesity and the potential need for much longer treatment, additional studies are required to investigate the efficacy and safety of the compound over longer periods.

We also monitored obesity-associated risk factors such as glucose and lipid metabolism. In earlier reports, it was argued that cathine and related compounds from khat leaves would deteriorate glucose tolerance and lipid metabolism, but there is also a report showing a beneficial effect [11]. In our study, there was no unfavorable effect of cathine at any dosage on the measured parameters of glucose and lipid metabolism. Even in the subgroup of people with type 2 diabetes, there was no evidence for a deterioration of metabolic control. However, it 
Hauner et al.: Efficacy and Safety of Cathine (Nor-Pseudoephedrine) in the Treatment of Obesity: A Randomized Dose-Finding Study

has to be noted that the current study is too small to clarify the metabolic effects of this compound.

Although the results of this trial may give some preliminary answers to old questions, they may also raise some new ones. If cathine has a potential for weight loss as indicated by this study, what is the best way of application and treatment duration, and what is the longterm benefit-risk ratio? Although the compound appears to be tolerated well, the question may arise as to whether it may convey similar risks for cardiovascular complications as reported for sibutramine due to its indirect sympathomimetic action. This is still an open question, as obese patients with elevated cardiovascular risk were intentionally excluded.

In conclusion, the results of this dose-finding study suggest that cathine has a potential for adjunct pharmacological treatment of obesity with an acceptable risk profile. In view of the still growing obesity epidemic, effective and safe treatment options are urgently needed, and based on the findings of this study cathine may deserve a more comprehensive exploration in larger clinical trials.

\section{Acknowledgements}

We thank the Riemser Pharma GmbH, Insel Riems, Germany for funding the study as well as all study participants for participation.

\section{Funding}

This study was funded by Riemser Pharma GmbH, Insel Riems, Germany

\section{Author Contributions}

HH and DW designed the study and prepared the protocol. HH, LH, ACS, JS, and MB performed the study and collected data. DW analyzed the data, and all other coauthors were involved in data interpretation. $\mathrm{HH}$ wrote the manuscript, and all authors reviewed the paper and gave final approval of the submitted version.

\section{Disclosure Statement}

Dr. Blüher reports grants from Riemser Pharma, during the conduct of the study; personal fees from Astra-Zeneca Pharma, grants and personal fees from Boehringer-Ingelheim/Lilly Pharma, personal fees from Novartis Pharma, grants and personal fees from Novo Nordisk Pharma, personal fees from Riemser Pharma, grants and personal fees from Sanofi Pharma, outside the submitted work. Dr. Hauner reports grants from Riemser Pharma, during the conduct of the study; grants from Certmedica, personal fees from Novo Nordisk and Orexigen, outside the submitted work. Dr. Jürgen Scholze reports grants from Riemser Pharma, during the conduct of the study. Other authors have nothing to declare.

\section{References}

1 WHO: Obesity and overweight, Fact sheet no. 311, updated June 2016. Available from: http://www.who.int/ mediacentre/factsheets/fs311/en/ (last accessed August 21, 2017).

-2 NCD Risk Factor Collaboration: Trends in adult body mass index in 200 countries from 1975 to 2014:a pooled analysis of 1598 population based measurement studies with 19.2 million participants. Lancet 2016;387: 1377-1396.

3 Caveney E, Caveney BJ, Somaratne R, Turner JR, Gourgiotis L. Pharmaceutical interventions for obesity: a public health perspective. Diabetes, Obes Metab 2011;13:490-497.

4 Walter CP, Bleska BE, Dorsch MP: Pharmacotherapy for weight loss: the cardiovascular effects of the old and new agents. J Clin Pharmacy Ther 2014;39:475-484. 
Hauner et al.: Efficacy and Safety of Cathine (Nor-Pseudoephedrine) in the Treatment of Obesity: A Randomized Dose-Finding Study

5 Toplak H, Woodward E, Yumuk V, Oppert JM, Halford JC, Frühbeck G: 2014 EASO position statement on the use of anti-obesity drugs. Obes Facts 2015;8:166-174.

6 Hauner H. Orlistat; in Hofbauer KG, Keller U, Boss O (eds): 'Pharmacotherapy of Obesity: Options and Alternatives.' Boca Raton, CRC Press, 2004, pp 219-244.

7 Henness S, Perry CM: Orlistat: a review of its use in the management of obesity. Drugs 2006;66:1625-1656.

-8 Pi-Sunyer X, Astrup A, Fujioka K, et al: A randomized, controlled trial of $3.0 \mathrm{mg}$ of liraglutide in weight management. N Engl J Med 2015;373:11-22.

-9 Kalix P: Pharmacological properties of the stimulant khat. Pharmacol Ther 1990;48:397-416.

-10 Balint EE, Falkay G, Balint GA: Khat - a controversial plant. Wien Klin Wochenschr 2009;121:604-614.

11 Al-Motarreb A, Al-Habori M, Broadley KJ: Khat chewing, cardiovascular diseases and other internal medical problems: the current situation and directions for future research. J Ethnopharmacol 2010;132:540-54.

12 Kelly JP: Cathinone derivatives: a review of their chemistry, pharmacology and toxicology. Drug Test Anal 2011;3:439-453.

13 Szelenyi I, Bräuer H: Kontrollierte Prüfung von d-Nor-Pseudoephedrin auf Effektivität und Unschädlichkeit. Wien Med Wochenschr 1974;124:49-52.

14 Spranger J, Dörken J: Kindliche Adipositas: Prüfung der Psychodynamik unter d-Norpseudoephedrin. Monatsschr Kinderheilk 1966;114:394-396.

15 Hauner H, Meier M, Wendland G, Kurscheid T, Lauterbach K; Study Group SA; SAT Study: Weight reduction by sibutramine in obese subjects in primary care medicine: the SAT Study. Exp Clin Endocrinol Diabetes 2004; 112:201-207.

$\rightarrow 16$ Bjelland J, Dahl AA, Haug TT, et al: The validity of the Hospital Anxiety and Depression Score: an undated literature review. J Psychosom Res 2002;52:69-77.

17 Riemser: Pharmacovigilance database of the Riemser Pharma GmbH.

18 Jordan J, Scholze J, Matiba B, Wirth A, Hauner H, Sharma AM: Influence of sibutramine on blood pressure: evidence from placebo-controlled trials. Int J Obes 2005;29:509-516.

19 James WP, Caterson ID, Coutinho W, Finer N, Van Gaal LF, Maggioni AP, et al: Effect of sibutramine on cardiovascular outcomes in overweight and obese subjects. N Engl J Med 2010;363:905-917. 